\title{
From Hopelessness to Expectation: An Interview with Christopher Cabaldon, Mayor of West Sacramento
}

\author{
By Monika Jansen
}

Christopher Cabaldon is the mayor of West Sacramento, a small town just over the river from California's capital city, Sacramento. Mayor Cabaldon received his Master of Public Policy and Administration (MPPA) in 1994 as part of the inaugural class of the program at California State University, Sacramento. He first became mayor of West Sacramento in 1998, and he was the first mayor directly elected by the citizens of West Sacramento in 2004.

West Sacramento is growing rapidly. Since 2000, the population has increased by over 50 percent, nearly reaching 50,000 at the time of the 2010 US Census. Changes in West Sacramento have come from the development of Southport, a new master-planned residential neighborhood on the south side of the city, as well as infill development in the center of town and in established neighborhoods. Retail has also moved into West Sacramento where there previously had been very little, anchored by Ikea and Target. In 2000, the River Cats, a minor league baseball team, came to town and moved into a new stadium in West Sacramento.

On March 13, Mayor Cabaldon spoke with Monika Jansen of Policy Perspectives over the phone to discuss his MPPA, executive leadership and democracy at the city level, his TEDx Talk from 2014, and his vision for West Sacramento.

\author{
Policy Perspectives: Why did you \\ choose to study public policy and \\ administration?
}

Christopher Cabaldon: I have been involved in public policy since I was a seventh grader, all the way through college, and into my first job working for the state legislature in California. Part of my portfolio there was running the higher education committee for the state assembly. In California, higher education involves principally three systems of public education, the UC [University of California], CSU [California State University], and community colleges. I had only had experience as a student at the $\mathrm{UC}$, and I wanted to experience the CSU directly. The reason I enrolled in the graduate program of Public Policy and Administration at CSU Sacramento was more for the experience of being a student at CSU than anything else. Having said that, I had been interested in the formal study of public policy since I was at Berkeley as an undergraduate, where I was an environmental economics major. The application of both the quantitative models and methodologies and the more formal theoretical models to public policymaking was a deep interest of mine from the time I was in college. So it made sense as a subject matter for me, but the real reason I pulled the trigger and enrolled in the 
program was to understand better what it was like to be a student in the state university system.

\section{PP: Has there ever been a moment when your degree was particularly useful?}

CC: There have certainly been moments where the value of [the MPPA] has been crystal clear. One example was in my very first term as mayor of West Sacramento, when we were in negotiations to build Raley Field, the professional baseball stadium for the AAA team in our city. It turned out to be a fantastic project for the city's economic development and stature in the region. But, at the time of the negotiations with the owner of the team there were a lot of analyses around the economic impact of the stadium; what the impact might be, what the multiplier effect of the city's investment might be-it was all part of the negotiations. I think if I'd been just any old regular style mayor, I would have put a lot more stock in the materials I was given by the team and the league. I had just done a project in my econometrics class, specifically on economic impact studies as they relate to public investment in professional sport facilities, and on how to do multipliereffect analysis. So, I approached a lot of the materials that I might have otherwise taken for granted more skeptically. My formal training and the application of the scholarly work in my graduate program turned out to be incredibly on point and helped craft the deal. I knew what to trust and what not to trust, and I wasn't going to pay that much attention to industry-generated multiplier effects and economic impacts. We knew that Sacramento would be the strongest minor league market in the country, so I knew fundamentally that the economics made sense, but it was really about what we were willing to negotiate. The team, just like every other team, was trying to get the best package and the highest level of subsidy from the public they could get. That's just Professional Sports Ownership 101. I didn't have a whole team of economists to back me up, but having had the graduate school experience directly in the field meant that I could enter those negotiations and drive the appropriately hard bargain.

PP: You have been mayor since 1998, but you were not directly elected by the people in West Sacramento until 2004. How did the change in the system come about?

CC: In most cities in California, in roughly two thirds or three quarters of cities in California, the mayor is elected by the city council, through a variety of mechanisms. Each city can do it a little bit differently, but the city council elects the mayor. That's how West Sacramento was, too. When I first became mayor [in 1998] it was because it was my turn. Every year, the council would pick a new mayor. As the Raley Field deal was put together, it became clear that this project would take longer than 12 months to get from start to finish, so the city council reelected me as mayor. Then, they did it again. After a while, the city council [decided that] the city performs better when we have some consistent, sustained leadership and a vision that our partners in the public and private sector could understand. It made sense for us to have a longerterm mayor, and if that was the case, then we should ask the voters. So, in early 2004, West Sacramento voted to make the mayor's position separate and elected by the people.

\section{PP: What are the advantages and} disadvantages of a rotating mayor 
versus a directly elected mayor?

CC: There really aren't any advantages to the rotating mayor system. When I first became mayor, I went to meet with the mayor of Sacramento. We each had our vice mayors with us, and the mayor of Sacramento says to us, "Which one of you is the mayor?" That should never be a position that you're in as a city. In that same meeting I wanted the mayor of Sacramento to agree to a couple of partnerships and projects, some of which would go in first in Sacramento and later in West Sacramento. That only works if the mayor of Sacramento believes I'm going to be around 14 months from now to deliver on my end. So much of whether there's a partnership or a private investor depends on the expectation that there's going to be long-term leadership. It's important for those potential investors or grant-makers or partners to know who the mayor is, and in most of those rotating mayor systems, no one knows who the mayor is other than the other council members. Since we did it, Elk Grove, which is the second largest city in in the region, adopted the same system. The campaign was, "We need to be more like West Sacramento," which was not something you would have ever heard 20 years ago. It was clear that [the voters of Elk Grove] understood that the difference between having an elected and not having an elected mayor was, in some sense, the difference between being a real city or not.

\section{PP: West Sacramento is in transition, and it seems like you have a clear vision for where the city is going. What is your vision, and what strate- gies have you used to accomplish this vision?}

$\mathrm{CC}$ : One of the core elements of my vision for the city has been creating a portfolio of diverse places and experiences in the community. We started off as one of the region's poorest cities. We had a tough reputation. We'd had a century of neglect and disinvestment. We had to fix stuff up just to get the basics, and then try to create a kind of place where you would spend your whole life. The vision that I talk about a lot is that we don't want to be one of those cities where it's all five-bedroom houses sitting up at the end of the cul-de-sac and there are only places designed for people who are 35 years old with exactly 2.5 kids. We don't want to be that place. We also don't want to be the place that's all apartments and feels like Manhattan, where you can't figure out how to raise a family or find a place for peace and quiet. Our vision is about creating diversity of places, where people of all backgrounds and aspirations and preferences and cultures can thrive and find a place for themselves. We don't force evolution in our city; we are trying to create the conditions for talented and creative people to make great things happen. We focus on results as opposed to the process. A lot of other communities are into community meetings and workshops and planning and task forces and consultant reports, and, no, that's not us.

\section{$P P:$ As you mentioned, West Sacra- mento used to have a tough reputa- tion. Now the reputation is of an up-and-coming, exciting new area. What has your office done to change the conversation?}

CC: [West Sacramento] is demonstrably and dramatically better in almost every dimension. There are more things to do and more places to go, and everything you would want in a community where you live or work has improved. The most fundamental 
change - and the thing that I'm the proudest of after a long time in office-is less the physical changes and more the community psychology, the sense of what's possible. Because of our poverty and our reputation, there was always a sense of utter desperation. People thought that things could be worse, but that they're not going to get any better because when you have a lot of diversity, immigration, poverty, and industry in a city, you just get what you get. Now there's a palpable sense everywhere in town that we've done a lot of great thingswhat can we do next? That attitude is important for sustainability. Change can't simply be about a single leader. That doesn't last. It has to be about changing the community psychology, which can only change by getting results and changing our reputation. I now serve a community that is confident in itself and believes in itself and, most importantly, believes in its future. Now the citizens demand that things keep getting better, and they are willing to contribute. So if I get hit by a light rail car tomorrow, I am very confident that the progress that we have made is going to continue. That wasn't the case when I started. Then, we just hoped we could get a couple of great things built just to prove to people who are doubters (which was essentially 100 percent of the people here) that something was possible. Now, that has happened. We've passed the inflection point between hopelessness and expectation.

PP: Since you became mayor, West Sacramento has added entire neighborhoods in the Southport area that are, on average, more affluent than the older neighborhoods on the north side of town. Are you concerned about the negative effects of gentrification in West Sacramento? Are you worried that affluent people will displace low-income families? Or that the needs of low-income families will not remain a high priority?

CC: When you're in Congress, you can be concerned about just a single dimension. You can say, what I'm really worried about is just gentrification. Or, there should be better public transit to serve low-income individuals. When you're actually in city hall, it's no longer a choice. If you want to have better bus service to provide better mobility and access for your low-income residents, the only solution is to figure out how to fund better bus service. In California, it's through sales taxes. You have to grow your sales tax base, which means you have to grow your sales. The most progressive thing that you can do in order to serve the mobility and job access needs of your transit-dependent constituents is to work on increasing retail sales. That's not something you would think about if you were in Congress, but when you're the mayor you have to make the connection. No issue stands all by itself.

The other part of your question about Southport-it's not really gentrification. Those are two different parts of a community. Southport is the suburban third of West Sacramento. It's not affecting the residential displacement of somebody in the Broderick neighborhood [in the center of town]. Those are distinct parts of the city. The gentrification issue becomes more apparent within neighborhoods. Within Broderick there is now a very high degree of development and projects and revitalization going on. It is a challenge, but in West Sacramento we have relatively high rates of homeownership, unlike places like San Francisco where the vast majority of your lowest-income individuals 
are renters and are therefore easily displaced. In a neighborhood like Broderick in West Sacramento, where a large proportion of even our poorest residents are homeowners, the displacement has to be mutually agreeable. It has to be, "I want to sell my house" as opposed to, "I'm being evicted." It's more a story of, if I sell my house, it's because I'm going to make a huge amount of money and it's going to finance my kids' college education. Having said that, most folks stay. We've had very little migration out of the city, even out of our lowest-income neighborhoods, because they are great places to live. Most of the development that's been occurring has been on empty parcels. We had such a legacy of disinvestment in our older neighborhoods before we became a city in 1987. So, there are a lot of unused or underutilized vacant parcels in the city, and that's where new development has happened. So, the typical things that you think about in terms of what's wrong with gentrification haven't really been occurring.

On the other hand, gentrification is really mainly the effect of folks who are driving up prices because they want to move into a place. It is because a place is attractive that it attracts people. If there are more people who want to live there than there's supply, demand is going to drive the price up. The only way to avoid that is for a place to be unattractive. That's a problem! Sometimes folks have a very simple approach to thinking about gentrification issues: they want no gentrification to occur. The only sure strategy for that is to allow neighborhoods that have been abandoned by governments for generations to remain abandoned. To continue to be undesirable and unattractive to live in. And that's not a moral choice to be made. We've had very few of the negative effects and we've had all the positive ones in terms of folks in our low-income neighborhoods getting additional boosts to their wealth. Folks are able to borrow or to sell and make investments in their kids. There is access to places to shop, to eat, to hang out with friends, to have a full quality of life that was not possible before. We definitely have our eye on the gentrification question, but we're nowhere near being a poster child for the toughest outcomes. I do think that gentrification requires a clear head and a recognition that every dimension of it involves trade-offs. There are no simple answers that both contribute to improving the quality of life for folks and making it so that nobody wants to live with them. That's not a possible outcome.

$P P:$ In your TEDx talk from last year, you talked about public participation and creating Democracy 2.0. You discussed issues with the public input process and pointed out that engaging with the community and getting the community to engage back requires more than transparency and information. Do you see social media as part of the solution to the problem?

CC: I do see it as a significant part. I see it as a failure when somebody shows up at a hearing at the city because I think, "Oh my god. It's that bad that you had to take off four hours of your life to come do this?" I don't see that as success. What I think success can look like in the engagement sphere is creating lots and lots of opportunities for low-stakes engagement. Rather than trying to get someone to come to a public hearing on the gigantic vote that's about to happen (even though the decision has already been made), why not make it 
easier for folks to express their preferences and desires on the fly, during their daily lives, and in ways that are convenient. Because that's really what we're trying to get at: what are the core values, what are the pain points, what are the aspirations of citizens? And that doesn't need to be framed necessarily as, "What do you think about the agenda item that the planning commission is about to consider?" Those are the kind of things that social media and, more generally, analytics and data are much better at divining. Similarly, if I want to watch a movie, I' $m$ better off having Netflix ask me a series of small questions and observing what I'm willing to share with them about my behavior and my choices than I am if I go to a Blockbuster brick-and-mortar store and sit there and be interviewed by a clerk. Because I don't actually know [what I want] in some cases. I haven't had the chance to explore any counterfactuals. I just know what's on my mind at the moment. Social media, to the extent that it can, does provide lots of casual, simple, short, low-attention-required opportunities for citizens to engage as an alternative. It just means that we have to be good at aggregating the information and analyzing it. But that's better than hearing a whole lot from a very small number of people in these gigantic one-shot opportunities at public hearings.

\section{$P P$ : In your TEDx talk you also dis- cussed how to "build a better sug- gestion box" through social media and other applications, but you said that it was not enough. What is the best way to move from a better sug- gestion box to Democracy 2.0? What would 2.0 look like?}

CC: Well, I don't know exactly. With social media you've hit on one element of it. Another element is to create the tools inside city hall to analyze what we're hearing from social media. We also have a lot of data that we don't pay attention to. For example, when we're going to create a new park and we' re figuring out, what should we have at this park? We know from history and datasets that if the neighborhood is surrounded by eight-story condo towers, it's more likely to need facilities for dogs than for kids. We can also tell from the demographics and from existing patterns of behavior who that park is more likely to be used by-if it's going to need a tot lot or a basketball court. We can tell that by looking at the vast amount of behavioral information that we already have from you as a resident and from your neighbors. But what we do instead is hold a public meeting in the neighborhood, and invariably what emerges is: it should be a tot lot. Because if one person in the room says that we really need to be taking care of our youngest residents, we quickly get to babies. If someone else in the room was thinking about a dog park, they shut up because if it's a choice between babies and dogs, of course it should be babies. You end up with a tot lot in a neighborhood with all dogs. You've wasted a lot of money on a playground and the dogs and their owners have nowhere to go. You end up with an efficiency problem. You also end up with a lot of equity problems because one fundamental role of government is to correct inequities. What you end up with when you go and ask people about the park is that no one ever suggests a basketball court. Why? Because folks are thinking about who is attracted to basketball courts versus who is attracted to tot lots. You end up, through public meetings, almost exclusively with tot lot parks. Then, when the kids get older we've got 
nothing for them. One of the answers, as I was suggesting in the lead-up to this, is the use of the data that we already have. It's not just abstract data, it is evidence of the actual intent and behaviors and choices that citizens make. It is what they want, even if we're not asking them directly, "What do you want?" Then, it may still be that we do a social media poll, or even a public meeting that says, "Here's what we've learned, here's what we think you want, are we right?" I think the use of lots of small cues is one way we might redesign the way that we think about democracy at the urban scale.

PP: I just have one more question. Are you planning to run for higher office?
CC: No. It's such an interesting question in what we think higher office really means. In part because the level of impact that I can have in my own community is much more profound than I can have in a "bigger pond." And, I' $m$ in a love affair with my town and what we're achieving. I really like getting results and this is a great venue to do it. West Sacramento has become a model for so many things, whether it's preschool or flood zone planning, which are recognized at the state and federal level. As a result, I get the option of working on state and federal policies in ways that most state legislators or even members of Congress can only dream of. I get the best of all worlds, and I get to do it with my neighbors. So, no, I have no intentions of moving to a different thing. 